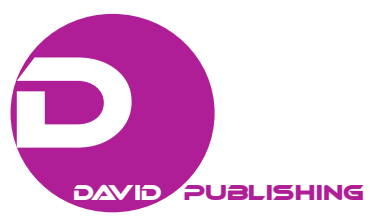

\title{
Technology and Society in the Digital Era
}

\author{
Amos Avny \\ Omnidev International, Yehud, Israel
}

\begin{abstract}
The article discusses the emergence of some major catches throughout the present digital era. It reviews the discrepancy between the technology rate of advancement and human-beings' ability to follow, comprehend, and adjust to it. This is, in essence, the articles' subject matter. Several issues are analyzed about their relationships with the technological advancement. Among them are: basic knowledge and trivia, high education, human-touch decreasing, communication and media, freedom and responsibility, culture, bureaucracy, and population inquiry methods. At the last section, the social-capitalism idea is presented and proposed to be the political-economic platform of contemporary era. The proposed manifesto, which rests on collaboration, balanced activity, and common interest, refers to the following points: a. Firm's goals should contain three elements ${ }^{1}$; b. competition is just one of other motivation factors; c. government involvement in economy is a real must; d. local and global considerations should be balanced; and e. social services as a security-net must be maintained. It is assumed that such a balanced policy will enable a continual course of creative prosperity combined with stable fair and happier life for all.
\end{abstract}

Keywords: technology, democracy, globalization, a balanced policy, government, economy, capitalism, socialism, social-capitalism, human ingenuity and welfare

\section{Introduction}

The digital era/age represents a remarkable period of many technological achievements. Technical accomplishments achieved during the past 50 years, well surpassed almost all the advancements invented from the early days of history, some 5,000 years back. This achievement just demonstrates the smartness and talent, ingenuity, and wisdom of the members of Western civilization. However, it is a sad fact that since the early days of civilization, a permanent race took place between technological advancement and people or society development. This unfortunate race took place from those early days when science, philosophy, and arts were created and executed by gifted individuals that were only few and scarce until today. It is a known fact that only a small number of scholars were able to write and read the scripts of the early Egyptians or the wit of the ancient Greeks. The rest of those people, the majority, remained illiterate and ignorant. Similarly, the printing technology that was invented in the 15th century and enabled books and printed matter to be more popular and available did not terminate illiteracy. Nevertheless, 500 years had to pass until, due to public schooling, education prevailed and illiteracy was defeated. Usually, throughout history, one can see that technology advances faster and more rapidly than the ability of human beings or societies to accept, practice, and maximize their use of it. This permanent gap between two of the leading trends in manhood grows even faster during the

Amos Avny, Dr., a senior management \& strategy consultant, Omnidev International, Yehud, Israel.

${ }^{1}$ A sound profitability, a social involvement, and true compliance with the environment requests. 
digital era of the 21st century.

The dramatic technological breakthrough occurred during the past 30 years enabled bridging this significant discrepancy. On the one hand, due to the dramatic development of the communication technology, many advanced communication devices became available for millions and millions of world's inhabitants. The TV and cellphone media changed significantly people' life all over the globe. The world became virtually a small village, where almost everyone is able to see, hear, and participate in global events. However, this bulk of information contributes less to increasing basic knowledge and enhancing scientific involvement and comprehension. Trivia games which became very popular and enjoyable business replace frequently deeper and more serious means for acquiring knowledge. Not too many are willing today to be involved in scientific research or philosophy studies. This inherent conflict, existing today between the instantaneous provision of trivial information, available in no-time, and the profound, conventional, consistent, and reliable scientific methods, required for technological advancement, worries the author. Therefore, it is the main concern of this paper. Some major aspects of this conflict are further discussed.

\section{Some Dilemmas and Catches of the Digital Era}

\section{Fast \& Popular Trivia vs. Conventional \& Basic Know-How}

Easy availability of data and speedy dissemination of information are among the characters that well typify the digital age. Naturally, these features have many good and helpful advantages, but they also hide some concealed dangers. Even throughout the daily talks, the pushy requirement for sending an immediate response decreases the responder's time for thinking. Words spring as fast reaction, usually indicate the shallowness of the answer. The prevailing cellphone civilization introduces into regular daily life, moods of fast reaction and immediate connection, and modes that previously were reserved for emergency and disastrous situations.

Whereas such a practice, sometimes not always, could be justified in the news networks, it should not be accepted in regular life. Some decades ago, International Business Machine (IBM) had introduced the simple slogan "Think". Unfortunately, one could admit that, at present times, it is even more relevant. The fact is that since people are requested hastening their response, so they have shorter time to think about it. No question that cellphone communication is very helpful and very effective in the business world. But, unfortunately, the picture in the social world is different. Talking fast with less thinking can well describe the nature of many social contacts in the digital age. Although this form of communication well describes the cellphone's communication, it infiltrates slowly but surely also to all other types of media. Many are impatient in listening while broadcasters and moderators sharpening and shortening their delivery. An old Jewish proverb states that "Wisdom is better delivered by moderate witty elders". The meaning is that hasty people have less time to think. The relevant question here is: Whether the cellphone's demands for immediate answer do not hurt the quality of the information? It is quite interesting to see and check this intimidating danger.

Such a simple and easy way for getting information and acquiring trivial knowledge by using the digital tools promotes a process of impinging and hurting the atmosphere of learning. It is quite a complicated and challenging process that may take two or three decades, until the right balance will be found. It should be a functional equilibrium between the information quality, the learners' eagerness, and service providing by the technological devices. 


\section{The Digital Era's High Education-Institutions \& Staff}

The rapid raise of global GNP per-capita during the past two decades dramatically increases the demand for all kinds of high education institutions in less developed countries (LDCs) and by the general public in the industrialist countries. However, this rapid expansion invoked some important issues:

a. Many institutions fail in redesigning their learning programs and reconstructing them in accordance with the available resources of the digital era technology. Too many institutions still enable their professors to deliver their teaching by reading sections of their 20 or 30 years old text books.

b. Universities are losing the traditional role as "bastions of knowledge or wisdom", since many other resources, at present, are open and available for the general public. In the digital era, a significant share of scientific knowledge and technological know-how is held in private and national agencies. As a result, preparing and producing new scores of qualified academicians remained the main job of many universities. The gloomy fact that many of the graduates do not fit to the demands of the digital era workplace does not bother universities too much.

c. The digital era's technology-oriented atmosphere and its mode of reaction do not always fit the traditional, conventional, and respectful style of academic life. This conflict has also a theoretical justification, whereas academic studies, achievements, and career rest mostly on past research, historical data, and previous accomplishments. The digital era performances are present- and future- oriented. A promising digital era's project must encourage curiosity, doubtfulness, and innovation. Digital era professors must be able to challenge the existing reality, be skeptic, and brave enough in order to be able to present new or different solutions. It is almost by the new era's definition that its followers should be non-conventional individuals who like to sky rocketing in their research. Naturally that type of academicians does not suit the traditional image of a university professor.

All the above obstacles, which basically characterize the digital era and the academia, should be taken in account when redesigning and orchestrating high schooling and social life of the 21st century coming decades. One of interesting initiatives for redesigning the teaching of economics in universities is done by the core team headed by Samuel Bowels from the Santa Fa Institute. This team published last year the book The Economy: Economics for a Changing World. Although the book hesitates to totally depart from the capitalist approach, it indicates how the classical attitude fails in solving many of present time's market failures. However, such initiative is very encouraging because every significant change required generating many supporters in order to start moving. As the Chinese proverb says: "Every long march starts with a small and tiny first step”, let us do the first step.

\section{Stylish Communication Devices Replace Human Touch}

From the early days of history, similar to other species, communication between individuals and groups was exercised by a variety of acoustic sounds, calls, and other audio noises. Disregarding the differences between human-beings, animals, and birds, all the sounds were produced and delivered by living creatures. When auxiliary gadgets, like drums or pipes, were used they acted as aids or amplifiers. The technological reality of the digital era changes this traditional reality. Human touch and personal linkage are decreasing down to almost a dangerous level. Public communication, which, in history, had witnessed monumental assemblies with outstanding orators, is almost totally diminished. Most of the audio messages are delivered at present by the TV and its supporting networks. Having a positive TV image and a good broadcasting ability is today 
almost the first prerequisite for every individual who seeks a public position. A very talented and able person who lacks these abilities must ask for a substantial assistance for helping him/her overcome this deficiency. On the personal level, due to the cellphone extraordinary development, people cut their direct speaking contacts while their use of the digital networks is growing exponentially. Talks within the family, parents' daily linkage with their children, neighbor's gossip, etc. are done through the cellphone without using any human note. Whether such a formal type of communication is good for either individuals or society is a serious issue. Whether and how it will affect future personal, familial, and social connections is an issue to be learnt and discussed.

\section{The Impacts of Technology on Social Values}

\section{Freedom vs. Discipline, Commitment, and Responsibility}

On the eve of the 21st century's digital era, major parts of world population experience freedom and feel themselves emancipated. This happened mostly because both of the technological advancement and democracy become the dominant form of government at most of the world nations. In the past, freedom was a covert dream, a desire, or a hope of slaves and vassals. The Great French Revolution had posed it (together with Equality and Fraternity) as a political goal for all the French deprived people. The American Civil War called to emancipate the black slaves while, in the 20th century, the decolonization movement fought for nation's political independence and freedom. From the 1960s, struggle in US was focused on getting colored people civil rights and promoting the antidiscrimination rules and regulations toward this goal. Throughout these hundred years, people and nations fought mainly for achieving a formal recognition and an official acknowledgement of their political and social rights.

Using Fukuyama’s (1993) “The End of History” metaphor, one may assume that the digital era symbolizes the end of many suffering phenomena, while witnessing large political liberty and the end of suppressions. Consequently, such freedom denotes the beginning of a new age. It is beyond the paper's scope contemplating on this hypothesis. However, as previous mentioned, the digital era, besides its substantial contribution to human-beings' health and welfare, evoked also many new problems.

Freedom was and still is, among the unique terms that represent a whole world of human dreams, aspirations and hopes. This is an exclusive value that empowered people and drove them all along history to struggle and achieve unbelievable accomplishments. There are many reasons thinking that, in the 21st century, due to the contemporary remarkable advancement of technology and the notable expansion of democracy, as the leading form of government, freedom, and liberty reach their highest level. Generations of freedom seekers were ready and willing to give their life for attaining this uplifted goal. At present, due to the dramatic expansion of advanced communication networks as the media influence grew exponentially, many former ground rules have to change dramatically. Values like freedom or liberty became very popular and are used frequently by more and more people. Advanced audio and visual means, available all over the globe, upsurge these feelings and encourage the popularity of these values even in less democratic states and in countries under autocratic regime. It seems that, toward 2020, there will not be any isolated nation that its people will totally be deprived from the main information channels. However, on other parts of the free world, common people who feel emancipated and liberated tend to think that freedom is unlimited, boundless, and unrestricted. Since we think that freedom is among the most important prerequisite for liberal advanced democracy, we present below some of its major dilemmas. 
Freedom, liberty, and emancipation are frequently concurrently used, while the exact meaning and the concrete connotation are absolutely not clear. Some radical fractions try to promote the idea that true freedom is the one of birds or fishes, which live in nature without any restraining forces. These types of anarchist groups forget or ignore the Darwin mode-of-survival that enables only the most competent and the strongest ones to survive. Since we reject both anarchy and suppression and we support the Western type of a liberal democracy - the best form of government for emancipated free people and ideas, we are requested to elaborate our perspectives and clarify our thoughts. Basically, freedom is a very complex expression with multifaced and dialectic meanings. It has both a rational and an emotional connotation. Its several meanings are based on frequent dichotomies and recurrent dilemmas. The meaning of freedom and its implementation changes from time to time and from place to place. Although freedom has a universal sense, it is still a social, cultural, and religious orientation, while its influence on science and technology is unclear and obscure. All in all, freedom and liberty have a significant spiritual, philosophical, and emotional impact on many aspects of human societies. As such, it should, therefore, be also qualified for acting as the leading essential and crucial guiding and supporting values for future advancement.

An interesting and a little different aspect of freedom, which relates mainly to work relationships is presented by Carney and Getz (2017) in their book by Freedom Inc. They argue that introducing and smart using of “corporate liberation” mode of operation improves the employees' mood, and by so doing, enhances their functioning and as result, the whole organization performs better. It is, therefore, a mutual interest, of both employees and management, to promote and run the "corporate liberation” technique, successfully. Some supporting explanations and justifications for these recommendations lay in the assumption that free employees tend to be more responsible and better aware for the results of their work. Thus, the message sent to every businessman, chief executive, or director,

select or carefully choose your staff or employees and then give them enough confidence and freedom to run the business properly. Tell them to make the maximum for attaining the agreed goals and let them use their own conscious for ensuring the results.

Freedom is not only a legal or a formal state of mind. The emotional intelligent school of thought teaches us how critical and crucial is the impact of feelings and emotions in the decision-making process. It is not enough to be officially a free individual. One has to incorporate freedom as a leading feature of his/her personality.

Unfortunately, it is not so easy. Freedom has to be implanted and embedded in children from their early days in the kindergarten. They have to feel the appropriate meaning of freedom even before they understand its formal definition. This is the right way for educating young and free people how to develop themselves and build a true great spirit and free soul. Since freedom is an acquired sense and trait, which is provide by both family and schools, the problem arises when one or even both are less-qualified for carrying out such an important mission. We argue that among the most important aspects of freedom, it rests the understanding that more personal freedom means more social restrictions and limitations. Many cases demonstrate this oxymoron. For example, in the wild nature and jungle, rules and modes of behavior are determined by the natural environment. In a civilized zoo or Safari, however, most rules and regulations are enforced by men/women. Increasing air or land traffic demands more rules and tougher regulations. A nomad can build his/her tent everywhere in the desert while civilized citizens must comply with their local rules. The mere and basic truth 
points out that freedom is a multi-facet expression. Thus, in the post-modern societies of today, societies that incline to exaggerate individualism must maintain a more balanced freedom. Free citizens in advanced democracies must accommodate this combined reality of freedom and responsibility. This basic and simple truth should be among the leading ideas of every democratic system.

\section{Technology and Culture}

Advance technology affects and touches culture and other types of human expression. However, cellphones, smartphones, and other variations of the electronic communication create a very complicated challenge for present genuine cultural life. These sophisticated means of today's technology endanger some basic components of civilization-They affect language and other types of verbal communication. Language in general, literature, poetry, theater, and drama in particular, all are based on verbal expressions. Although the digital era's smartphone revolution increased and, significantly, the availability of information encouraged the democratization of knowledge, it also caused the swallowing process of information. People can gather much information within a very short time, but it worth less; it heard frequently, like hearsay.

Additionally, but more dangerous, the daily popular use of the smartphones verbal expressions creates unintentionally, a new jargon constructed of abbreviations, half words, and other bizarre signals. It makes sense to assume that with the time going by this distorted jargon of half words will become the main language of the land. The present Western civilization rested and grew from texts authored hundred years ago. William Shakespeare, Jan Jack Russo, and other Renascence writers laid the ground for present culture. In many respect, language is the principal base and the essential foundation for any type of cultural activity. Using proper language is also among the prerequisite for conducting research and promoting science. Whether the smartphones' jargon can or will be able in the future, to properly fulfill the above undertakings is a matter of time and belief.

\section{Technology and Bureaucracy}

Every organization has its own bureaucracy. It started some thousand years ago, with Moshe who accepted his father-in-law Jethro's advice and placed over his people "rulers of thousands, and rulers of hundreds, rulers of fifties and rulers of tens" (Exodos, 18, para. 21). The modern form of bureaucracy was offered by Max Weber, who published his theory at the end of the 19th century (Weber, 1979). Despite numerous declarations of politicians that were derived from real and long practical experience, bureaucracies, in general, preserved and upheld their organization's interests rather than promote and protect their customers/citizens' interests.

Regimes and governments perpetually tried to change or cure those situations, but, unfortunately, little was changed. The digital era's technologies enable to improve the bureaucracy and citizens connections by providing a two-tier system. Converting many civic information and administrative forms into digital information transferred by computers and smartphone was the first and main channel. Professionally this alternative which increases the use of digital networks is named e-government. Using thoroughly this option reduces significantly the customer's need to meet personally the bureaucrat. This is like a digital emancipation. The banking industry which is an essential participant in the digital transformation is experiencing a digitation of many of its services. In fact, even today, one can pay, transfer, or invest money without visiting his/her bank's office. These operations and many similar can be executed by using the cellphone alone. Banks assume that this change would save them many expenses and will help them coping with their competitors. However, the banking services digitation, besides its advantages, must also overcome some critical hurdles. It is fair to 
assume that during the coming two decades, about 200 million customers, in America and in Europe, especially elders and less competent citizens, we will need personal assistance for conducting their relationships with the banks. This assistance should be provided by either public services or private firms.

The second way for limiting the bureaucracy power is by designated legalization. The social-capitalism theorem (detailed in Section "Traditional Capitalism and Socialism Are out") recommends to establish, in all large organizations, a permanent working committee for exceptional cases. Such a committee will permanently meet and discuss the cases that did not pass the regular and automatic tracks of the e-government bureaucracy. Understandingly, the whole process will work within a firm time-table. There is no guarantee that the above two-tier track will work efficiently since bureaucrats will fight strongly to preserve in their hands maximum power. However, the rewards are so promising that it justifies trying.

\section{Technology-Oriented Population's Inquiry}

As previously discussed, the digital era is the product of two parallel processes: the recent technological outbreak and the supremacy of democracy as the dominant form of government. As a result, more people around the world, men and women, feel themselves liberated and have the time, the means, and the opportunities for practicing their rights. In a way, one may argue that this emancipation process elevated the personal individualism and grant it more strength. From many aspects, this is a remarkable accomplishment, which generations in the past, hoped, dreamt, and rarely believed in its coming.

However, this process has evoked also some cardinal contradiction that is still kept covered in tinkers and philosophers' mind. The common democratic wisdom states that “all people are equal”. Nobody today is ready to explain or better define the meaning of such an equality. Politicians, academia, social activists, laymen, and everyone of this group have its own idea about the real meaning of equality. They use different aspects of this term for promoting and endorsing their specific political or social agendas. We challenge this common swallow or political oriented approach. An old Jewish proverb says that: "People's internal personality differs as their external appearance does". As in life, there are short and tall, slim and fat individuals; similarly, there are smart and fool, able and less able persons. Thus, we argue that human societies should be analyzed by using scientific and technology-oriented methods, such as Normal Distribution Theorem and described by The Bell-Shaped Curve. This theorem claims that like other living creatures, human population should be divided mainly into three major groups: one small group rests on the lower end, the second majority group lays in the middle, and the third, also a minority group, is placed on at the upper end. The Bell-Shaped Curve below well describes this perspective. 


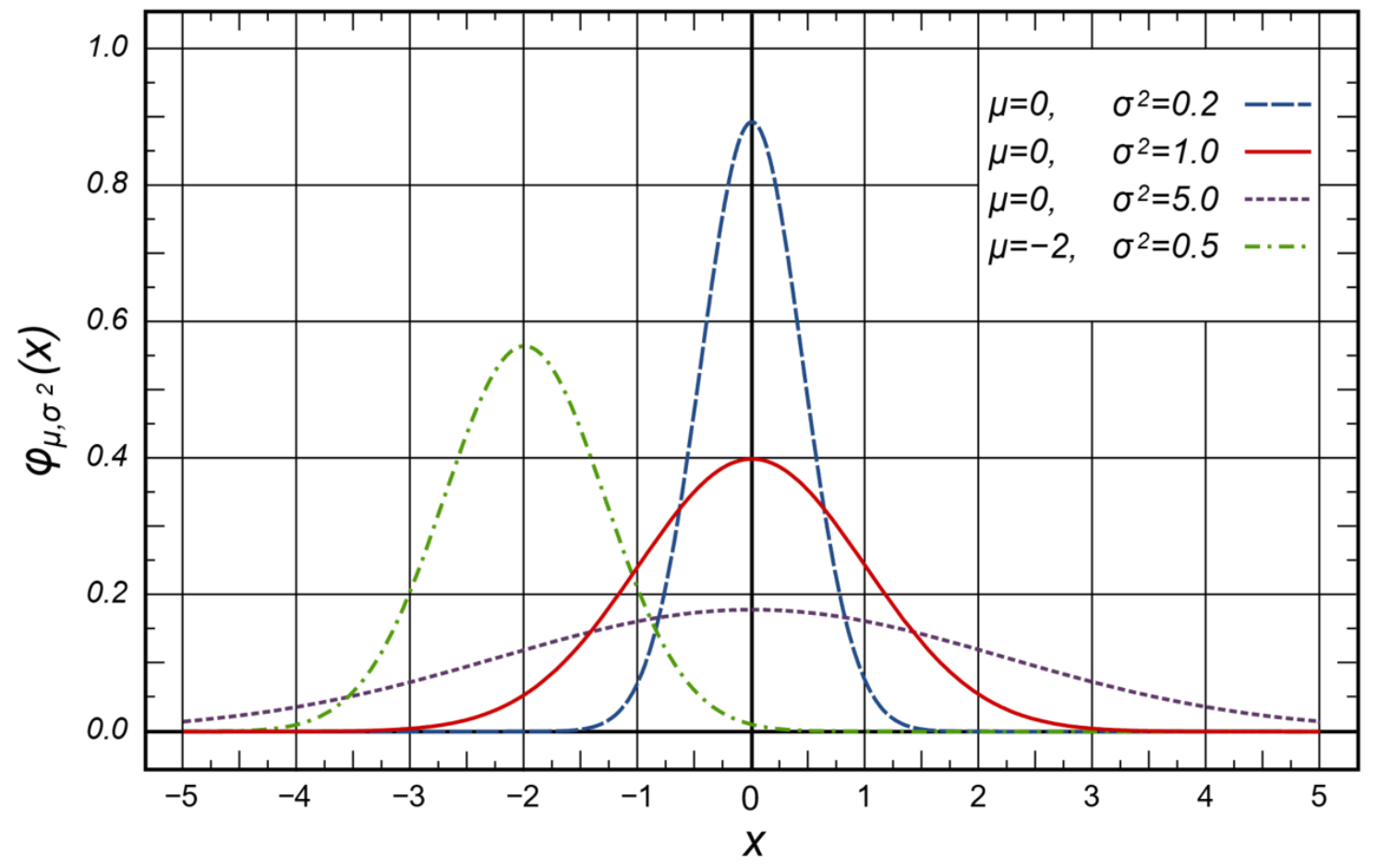

Figure 1. Three variations of a Bell-Shaped Curve.

Notes.

1. The lowest curve represents a large, normal population, which is quite homogeneous. It contains a variety of individuals who are similar but slightly different.

2. The second curve, the (-2) centered one, represents also a normal distributed population, which have a significant common characteristic but is slightly smaller than the average, shorter or slim appearance, for example.

3. The third curve, the tallest one, represents a small specific group like Ph.D. students, body builders, or ballet dancers, which represents very small but homogenous population, and contains little extreme ends and very similar individuals. The above curves just indicate how different populations are distributed but have nothing to say about the quality, and the ability concealed in every individual.

Unfortunately, many professors and social activists deny the Normal Distribution Approach and negate any attempt to reorient the approach of population studies. They are stuck with the former maxim of "all people are equal", which was relevant 30-50 years ago, at the time of the struggle for equal civil rights. When confronting the Normal Distribution Analysis (or Bell-Shaped Curve) with other measures of population, relevant for democratic nations, we face an interesting unsolved issue. While the democratic measures state that all people are the same, the Normal Distribution Theorem argues differently. It states that populations are distributed normally, according to their own specific type of personality. Moreover, a digital era's society, either a nation or an organization that wishes to grow and prosper, is required and is demanded to generate all available resources. The most crucial and scarce resource are gifted people who should be assessed individually and according to their own personal faculties. Any collective or equal evaluation will fail to provide the best results. Gifted football players and ballet dancers, as are theoretical mathematicians, should be assigned to work in accordance with their natural talent and acquired skills. Society will only win when its members will be employed according to their ability, ingenuity, and natural faculties. Human-beings are born, naturally, when some are prettier, some less nice, and few exceptional. Digital era's society must find the way for maximizing 
the contribution of every different individual to the general good. Focusing on normal distribution of individuals' talent and skill enables to enhance the performance of the whole. In sum, whereas the traditional equality approach results with ordinariness and mediocrity the National Distribution Method leads to ingenuity and excellence.

How to bring this observation to the public eye is a very important issue, but it is beyond the scope of this paper.

\section{Social-Capitalism-The Manifest of the Digital Era}

Referring to the basic issue of technology-society's influences, impacts or relationships lead to assume that advanced technology demands the development of a revised political-economy policy. New machines, instruments, and networks accompanied by new modes of operation demand the embarkment of renewed practicing procedures and novel instruction books. The social-capitalism thesis is among the pioneers who meet this demand and tries to fulfil it. Five major principles of the proposed policy are detailed further.

\section{Traditional Capitalism and Socialism Are out}

The fading out of the former classical two big ideologies, capitalism, and socialism, is one of the remarkable consequences caused by the technological advancement and the knowledge democratization processes. The above two ideologies came to their highest point during the 20th century where they were defined and described by a formalistic set of rules and directives. These conditions have been changed in the 21st century, when the chaos perspective took the lead and the transformation process is almost the only certain phenomenon. As previously mentioned, due to technology and democracy, while more people are more educated, amounts of information are more available, and people tend to ignore ideological teaching. Many choose their leaders by sympathy, media appearance, and oratory. Affiliation with political parties loses their appeal and less and less individuals seek it. The election of President Donald Trump in US, President Macron in France, and the irrational Brexit decision in UK, just demonstrates how popular this trend is. Another, a more significant reason for the above socio-economic change is the disappearance of many of the major classical and traditional characteristics characterizing both capitalism and socialism. Five major features of social-capitalism that fit the digital era and demonstrate the said change are further discussed.

Social-capitalism-A manifesto for the digital era. The following principles are offered as revised building blocks upon which the digital era's society should be conducted.

- The firm's goal is a combination of three leading factors.

The effect of technology, democracy, and globalization processes and their combined impact on the 21st century societies, differ remarkably from those of prior periods. People in many parts of the globe are more liberated; they have increased their income and developed higher inspirations. However, due to the collapse of the two major political-economy perceptions-socialism and capitalism, the world is seeking a new reformed standpoint that will challenge the coming days. Social-capitalism is among the leading candidates for fulfilling this crucial mission. It is our sincere belief that freedom and liberty can well be incorporated within the leading values of this perspective. Consequently, some of the major characteristics of the proposed thesis are detailed below.

a. Advancement through collaboration and cooperation;

b. Growth by balanced and people-oriented approaches; 
c. A permanent effort to protect the environment.

Most Western schools of business, in the 20th century, teach that every economic enterprise or a firm has one main goal-making money and producing revenues. This was, and still is, the first and ultimate commandment of every individual who is involved in economic activity. This is also the capitalism's major dictate. Capitalists, in general, erroneously, saw making money and profit as the leading supreme reason of life. In the digital era of the 21st century, however, this ultimate directive is changing. Today, every firm is required to meet a triad goal constructed of three aims:

a. being economically sound and efficient;

b. actively be involved in social and communal life;

c. strictly complying with the environment protection ruling.

Nobody, small or large firms, private or public enterprise, is allowed to disregard these three requirements. The best business opportunity will be denied if it fails meeting one of the above demands.

- Competition is no more the leader, but just one of many motivation factors.

Competition is among the most popular terms used for describing the nature of capitalism. Even some socialists tended to promote this type of behavior. Many classical theories, textbooks, and lectures were published about the crucial role of this mode of operation as the driving power of every economic operation. Actually, traditional economists saw competition as a panacea and a remedy for many economic shortages and sicknesses. Capitalists like to use it as an intimidation mean against public and social enterprises. History teaches that when our olden fore-fathers stopped competing, quarreling, and fighting between themselves, and turned to work together and cooperate they have made the first step to progress. The very early ancient tribes understood that only collaboration and common effort may assist them in their fights for emancipation. Bowles, Edwards, and Roosevelt (2005) supported this argument by saying: "in competition among groups, those whose members have learned how to operate-that is, not to compete with one another-often win” (p. 50). Unfortunately, some thousand years had to pass until ordinary people will realize that the brutal competition maintained by the capitalist teaching is just a sophisticated instrument for abusing the poor and enriching the rich.

Anyway, it is well understood that such an approach does not fit any more to the situation in the digital era. Furthermore, it seems logically assessing competitiveness, as one out of many components or traits, constituting individual's personality. It acts like prudence, initiative, ambition, entrepreneurship, and other human features. We believe that individuals are constructed of a given mix of traits and faculties, which steer their behavior and control their acts. Competitiveness, by no means is not always the leading or the dominant one. Therefore, competition in the digital era is no more the sole and explicit motivation factor and the driving engine, which pushes to success. There are other, not weaker, ways for harnessing individuals' initiatives to maximizing their achievements.

During the previous century, few dared to claim that economic operation can be driven by teamwork or collaboration. However, the 21st century's complicated projects in science, technology, medicine, etc. well demonstrate the need for such an effort.

Teamwork is required for sending men to the moon, for exploring the oceans' deep water, for running a chirurgic procedure, and for presenting a show on Broadway. Even the automobile industry that was among the firsts to build and use the assembly line technique moves today forward and promotes teamwork and synergy. 
Moreover, free competition does not real exist in two of the symbolic banners of the free market faith, namely, the farmers' open markets and the taxi services. Even their prices are determined, openly or covertly, neither by the "market forces", nor by the customers, but, rather, by a concealed body owned by the traders, which control the market prices, daily and even hourly. All in all, competition remains a buzz word, which all types of preachers like to use; small businesses try to maintain it while the big businesses have enough ways to circumvent around it. In the real business world, competition is just one among several modes of operation used in different ways and has little to be regarded as a symbol of capitalism.

- Government involvement in the economy is a fact.

Among the leading capitalism lines of thought and the teachings of the proponents of the free market supremacy, governments should never be involved in economic life. They believe and preach that the markets' forces should take care and steer all economic activities. The 21st century's economic, financing, and business occurrences negate this claim and emphasize the crucial and vital role of governments in the national and international economies. Despite the teaching of prominent professor and TV's popular orators on free market economy, the real world clearly indicates that economy cannot properly function without a significant government involvement. US Presidents George W. Bush and Barak Obama' intervention in the 2008-2009 Financial Crisis is just a typical example of the policy required. Despite the orthodox capitalist academicians' teaching, they did not hesitate in purring millions of public dollars into private banks and large corporations. Without such a significant assistance, many large banks and great manufacturing industries would had falling apart. President Donald Trump calls for "America First" is another indicative symbol for the meaningful involvement of government in the main course of the national economy. It also clearly indicates that national interests come first and precede global concerns. How ironic is it that such a declaration comes from a prominent advocate of the capitalism school of thought? The rapid development of nations in South-East Asia is another example of successful cooperation between governments and the big business. Thus, it is quite natural to claim that at the digital era, world governments must cooperate with private sector and both of them must find way for incorporating in their business the third (not for profit-NGOs) sector. The theoretical separation between the business world and government agencies is not working any more. It will be very useful if classical economy's professors will learn from this real movement and will change their teaching accordingly. The known public private partnership (PPP) is going to be one of the major avenues for executing future activities.

- Nationalism grows as globalization loses its promise.

At the end of the Cold War and the diminishing of the communist threat, Western capitalism promoted foreign trade and endorsed globalization. This modernized version of international trade increased significantly. Its volumes grew while moving many production lines from industrial nations to less-developed countries (LDCs), mainly to China and other countries in South-East Asia. Although the globalization increased the income of LDCs' citizens, it reduced the availability of well-paid jobs in the industrial nations. Additionally, it endangered the life of many light, small and medium industries in those countries. As a result, appeared groups of disappointed citizens who call to promote national interests and endorsing local industries. The electing of President Donald Trump in US and the bizarre victory of the Brexit movement in US are just two examples of this tendency. President Donald Trump, a prominent advocate of the classical capitalism, does not hesitate too long before openly disregard one of its major principles—the Free Trade Maxim. By claiming “America First” President Trump publicly ignored the Free Trade Axiom and favored local interests. It is a matter of common 
wisdom that countries in South-East Asia, which openly support free international trade, covertly and consistency support national business interests. When American captains of capitalism justify the notion of "America First", there is no reason for negating it from other nations. Albania or Bulgaria, Czech Republicor Denmark, Estonia or Finland, etc. all should be able to use their governments for encouraging and developing their own economies.

Thus, globalization and free trade moves, which theoretically may maximize benefits to all nations, actually help and enrich mostly the rich and wealthy. This is another reason why at this time more citizens prefer local initiatives than global activities. Contemporary nationalism trends incline also to support and encourage these tendencies.

- Social services were adopted by most nations.

The socialist idea that governments should take care of their citizens, vehemently rejected by prominent capitalists, became a winning reality by most of the world nations. There are only few known nations that follow the capitalist notion of ignoring welfare support. Although differences exist among the running systems, but most democratic countries have some kind of social security systems, pension or retirement programs, some types of public health organizations, and sick, handicaps, and disables support systems. Public schooling systems expand also while many countries establish babies and toddlers' education kindergartens. Most advanced capitalist regimes maintain and even enhance social services, former established by socialist parties, in order to meet their citizens' demand.

In sum, the present significant advancement of technology, the rapid expansion of the democratization, and the globalization processes, hastened the emerging of a renewed political-economy perspective-The social-capitalism outlook. It rests on the above-mentioned main points, containing more issues and offering a novel viewpoint bases on social/capital collaboration, moderation, and common interest. It is assumed that as technology advances so fast ahead, human and social elements should change their past behaviors and will better embrace modes for running their life (Avny, 2016).

\section{Conclusions}

All will agree that technology and democracy grew to be among the most significant determinants of social life at the 21st century digital era. Both processes pour new fresh meanings to life of millions. The actual progress is so remarkable that it surpasses the dreams of many previous imaginative dreamers. However, most people and societies were not, and still are not, properly prepared for these dramatic changes. Suppressed and enslaved individuals never were taught how to conduct life after the emancipation. Similarly, nobody taught people how to use smartphones. As a result of these less-professional uses, many embarrassing phenomena occurred and some distressing gap was created between people and their technical environment. This paper reviews some of the major short-hands and examines the intimidating dangers. The article concludes with offering a revised political-economic manifesto-the social-capitalism idea—an attempt offering revised political-economic platform, adjusts-for the digital era.

\section{References}

American Bible Society. (1999). Holy Bible: King James version. New York: American Bible Society. Avny, A. (2010). Social-capitalism: The new socio-economic set-up. International Journal of liability and Science Inquiry (IJLSE), February. 
Avny, A. (2016). Essays of a senior optimist: The social-capitalism idea is a promising hope. Germany: Lap-Lambert. Bowles, S., Carlin, W., \& Stevens. M. (2017). The economy: Economics for a changing world. Boston: Oxford University Press. Bowles, S., Edwards, R., \& Roosevelt, F. (2005). Understanding capitalism: Competition, command, and change (3rd ed.). Boston: Oxford University Press.

Carney, M. B., \& Getz, I. (2015). How corporate liberation unleashes employee potential and business performance? Tel Aviv: Freedom Inc.

Fukuyama, F. (1992). The end of history and the last man. Tel Aviv: Or Am Publishing House.

Weber, M. (1979). Bureaucracy. In J. M. Shafritz and A. C. Hyde (Eds.), Classics of public administration (2nd ed.). Chicago: The Dorsey Press. 